\title{
Current Topics
}

\section{Challenge of Mass Spectrometry toward the Elucidation of Life Phenomena}

\section{Development of Imaging Mass Spectrometry}

\author{
Yusuke Saito, Michihiko Waki, Saira Hameed, Takahiro Hayasaka, and \\ Mitsutoshi Setou* \\ Department of Cell Biology and Anatomy, Hamamatsu University School of Medicine; \\ 1-20-1 Handayama, Higashi-ku, Hamamatsu, Shizuoka 431-3192, Japan. \\ Received February 3, 2012
}

\begin{abstract}
We have developed a mass microscope in which a microscope is combined with high-resolution matrix assisted laser desorption/ionization-imaging mass spectrometry (MALDI-IMS). This technique is a powerful tool for investigating the spatial distribution of biomolecules without the need for any time-consuming extraction, purification, and labeling procedures for biological tissue sections. The mass microscope provides clear images with regards to the distribution of hundreds of biomolecules in a single measurement, and also helps in determining the cellular profile of the biological system. In this review, we focus on some of the recent developments in clinical applications and describe how the mass microscope can be employed to assess pathomorphology and pharmacokinetics.
\end{abstract}

Key words imaging; mass spectrometry; microscopy; analytical biochemistry; drug kinetics

\section{INTRODUCTION}

Imaging is a technique that can be used to visualize cellular and molecular processes that occur in living organisms in a two-dimensional (2-D) or three-dimensional (3-D) fashion, without perturbing the structure of the system. The various techniques currently available include X-rays, ${ }^{1)}$ nuclear magnetic resonance, ${ }^{2)}$ cryo-electron microscopes, ${ }^{3)}$ positron emission tomography, ${ }^{4)}$ immunohistochemistry, ${ }^{5-8)}$ green fluorescent protein labeling, ${ }^{9-12)}$ and luciferase. ${ }^{13)}$ The green fluorescent protein labeling technique involves over expression of the fusion protein of the concerned molecule and green fluorescent protein. ${ }^{12,14)}$ However, these techniques can only provide information on the structure of the material. There is also a "nonlabeling" technique even at the electron microscopic level, ${ }^{3)}$ and yet there is still a serious limitation on the object preference. Imaging mass spectrometry (IMS) ${ }^{15}$ is an emerging technique that is expected to at once resolve these problems in conventional morphological examinations. In IMS, mass spectra associated with spatial information can be simultaneously recorded to obtain expression patterns of various molecules in specimens to be analyzed. This new generation of mass spectrometry (MS) has been used for the analysis of biological compounds at either the tissue ${ }^{16-19)}$ or single-cell level. ${ }^{20-23)}$ Recent IMS studies have been conducted on a variety of topics, including biological applications ${ }^{24-30}$ ) and pathological applications. ${ }^{31,32)}$ In addition to the analysis of protein described in the above references, direct lipid analysis in mammalian tissues ${ }^{33,34)}$ has also been conducted, and histopathological materials ${ }^{35)}$ and pharmacokinetics in rat whole body sections ${ }^{36)}$ have been studied.

IMS can be used to visualize the spatial distribution of biomolecules based on the mass-to-charge ratio $(\mathrm{m} / \mathrm{z})$ of the target molecule in the mass spectrum. Several ionization methods, such as desorption electrospray ionization (DESI), ${ }^{37}$ secondary ion mass spectrometry (SIMS), ${ }^{38)}$ and matrix-assisted laser desorption/ionization (MALDI) have been investigated. ${ }^{39)}$ DESI is an ionization technique by which the molecules are ionized without addition of organic matrix under ambient conditions. In this method, the surface of the sample is analyzed by charged droplets of solvent, generated during the electrospraying. DESI has a limited spatial resolution of $0.3-0.5 \mathrm{~mm}$, which is not a sufficiently high resolution for imaging. SIMS on the ion microprobe offers the best combination of spatial resolution $(20 \mu \mathrm{m}$ beam diameter) and precision ( 0.2 per $\mathrm{mL}$ for sulfur isotopes). This technique is applicable for the analysis of small molecules $(<1 \mathrm{kDa})$ because the high energy of the SIMS causes the fragmentation of larger molecules. On the other hand, MALDI is used to visualize biomolecules such as lipids less than $1 \mathrm{kDa}$ as well as peptides and proteins over $10 \mathrm{kDa}$.

MALDI-IMS is a powerful tool that allows the simultaneous mapping of hundreds of molecules in a tissue section in a single measurement. To use a mass spectrometer as an imaging instrument, it is essential for the spectrometer to be equipped with an automatic rastering function, automatic data acquisition system, and visualization software. Recently, several manufacturers have released novel instruments having these features. Almost all manufacturers have developed in-house software for their instruments and have included a driver for instrument and image reconstruction. On the other hand, the user-friendly visualization software BioMap ${ }^{40}$ ) is freely available; it is used commonly in mass imaging (MALDI MSI HP, http://www.maldi-msi.org/content).

Our group has developed the original equipment in collaboration with Shimadzu Corporation of Japan and extended the techniques for molecular profiling of different tissue samples, such as brain, ${ }^{41-43)}$ liver, ${ }^{44)}$ testis, ${ }^{45)}$ and retina ${ }^{46)}$ of mice, and colon cancer in human, ${ }^{47)}$ involving sample preparation, ${ }^{25,48-50)}$ and the nanoparticle-based ionization process in IMS. ${ }^{51-53)}$ In 


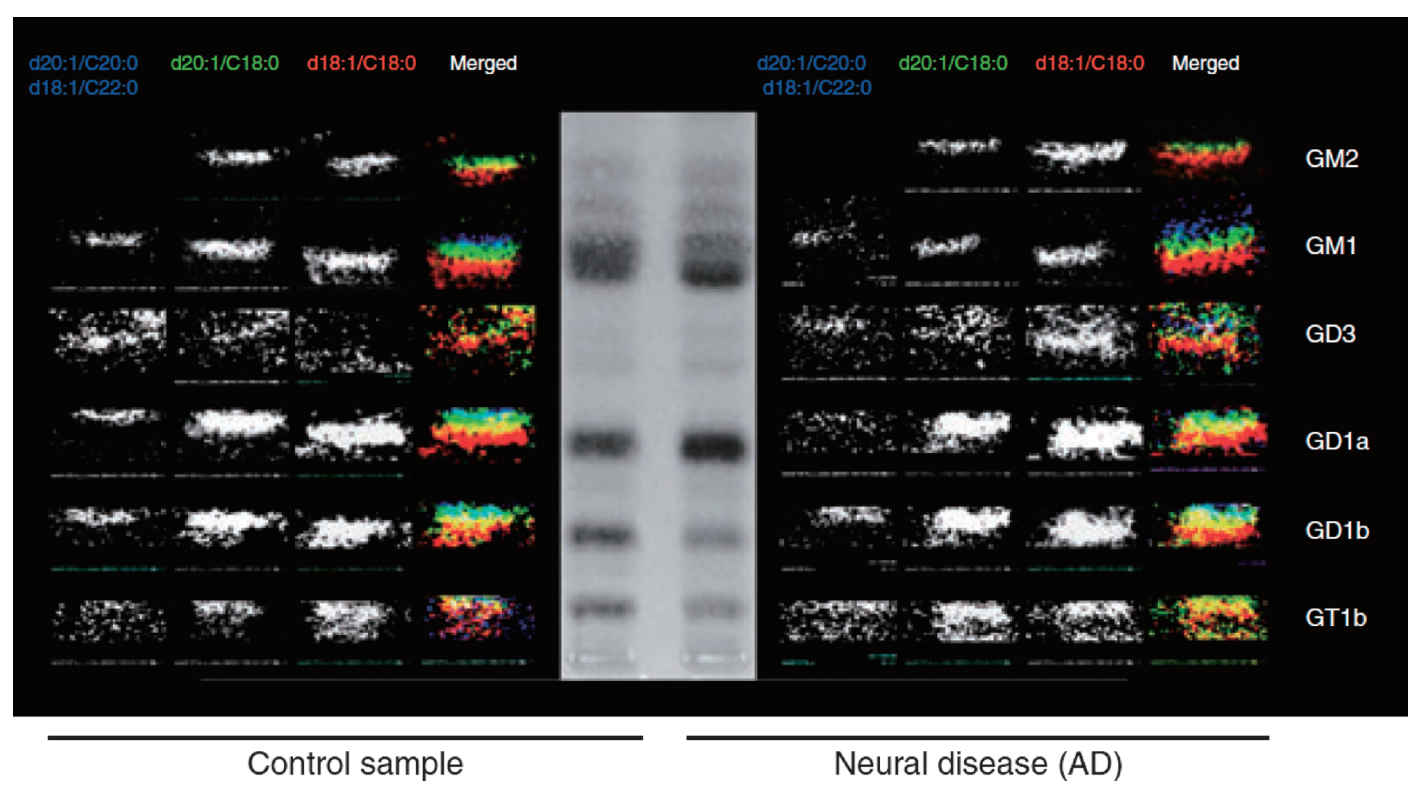

Fig. 1. TLC-Blot-MALDI-QIT-TOF-MS Imaging of Hippocampus Gray Matter Gangliosides

The raster scan of the polyvinylidene difluoride membrane was performed automatically. The number of laser irradiations was 5 shots in each spot. The interval of data points was $200 \mathrm{~lm}$. The color red indicates a d18:1 sphingosine-containing signal, the color green a d20:1 sphingosine-containing signal, and the color blue a d18:1/C22:0or d20:1/C20:0-containing signal. Merged images of these are shown on the right side of each panel. (Reprinted from ref. 60 with permission from Blackwell Publishing.)

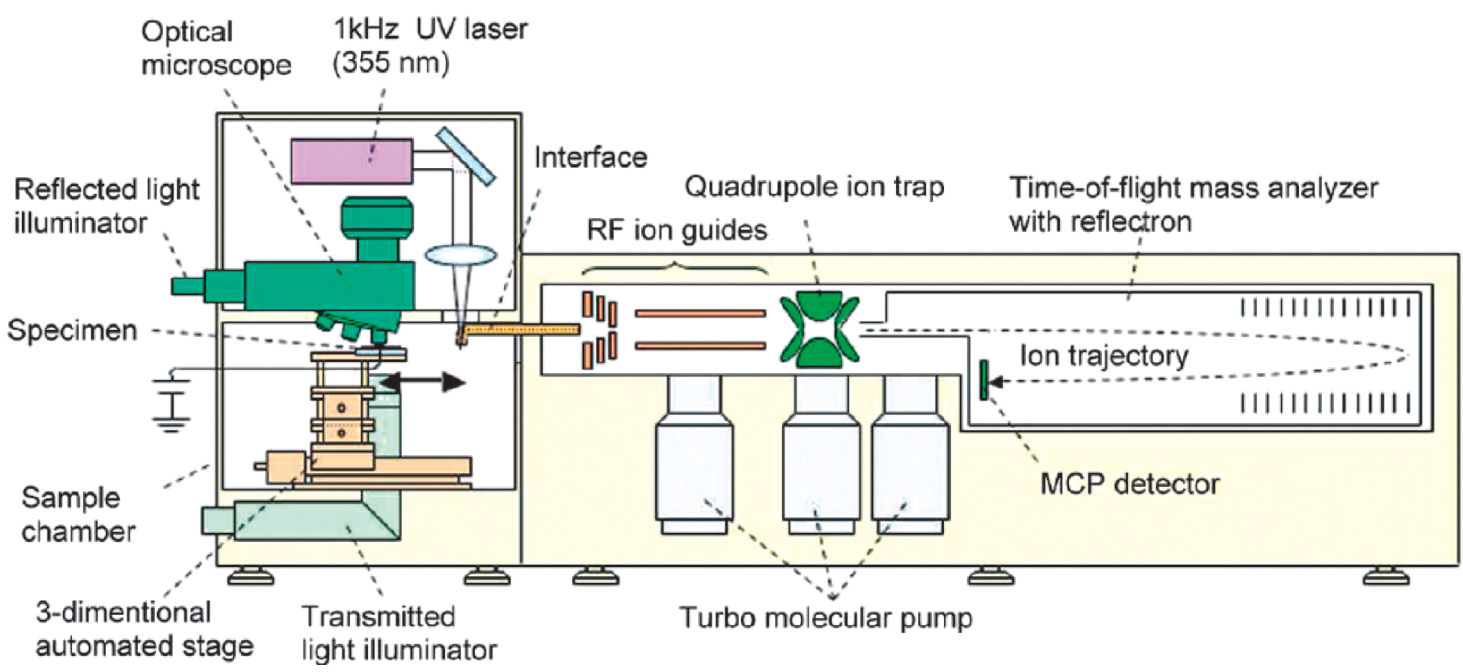

Fig. 2. Schematic Diagram Showing the Mass Microscope

(Reprinted from ref. 66 with permission from the American Chemical Society.)

recent years, MALDI imaging has resulted in many developments for assessing the localization of molecular species in biological samples. Several applications represent the direct entailment of this technology to basic clinical research. Here, we discuss the recent developments concerning MALDI-IMS.

\section{TARGETS OF ANALYSIS BY MALDI-IMS}

2.1. Imaging of Glycosphingolipids Glycosphingolipids (GSLs) play important roles in various brain functions. To investigate the mechanisms of brain function in more detail, it is necessary to understand the composition and function of GSLs. We have studied GSLs in previous research. ${ }^{6,14,54,55)}$ Thin-layer chromatography (TLC) is routinely used for the separation and partial characterization of neutral and acidic
GSLs and phospholipids in mixtures. ${ }^{56-58)}$ However, even under optimized TLC conditions, TLC characterization of individual GSLs does not yield unambiguous structural information. Information regarding the compositions of these highly complex mixtures remains limited. The same sugar moiety in different GSLs may migrate to different positions owing to differences in their ceramide structures. Multi-stage MS $\left(\mathrm{MS}^{n}\right)$ analysis can supply information on each ceramide structure. However, it is difficult to identify individual molecular species by MS alone. Therefore, by combining TLC and MS, we were able to obtain a complete set of information on GSLs.

Our group has used MALDI-MS/MS to study colon cancer liver metastasis in $3 \mu \mathrm{m}$ thick tissue sections. MS/ MS investigations of normal and cancerous cells revealed 

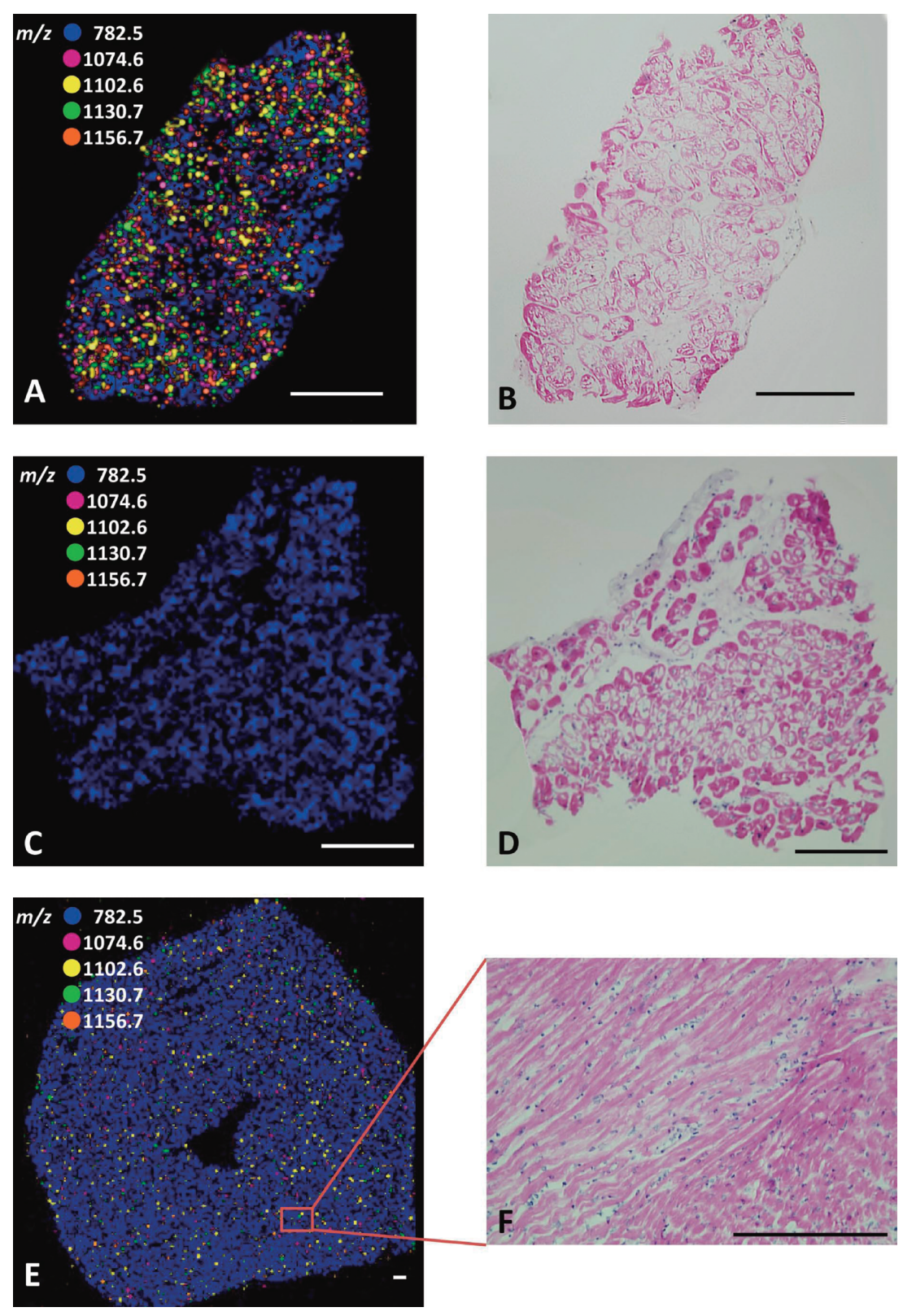

Fig. 3. IMS and Histology of the Samples

We constructed a figure by plotting the positions of the $\mathrm{m} / \mathrm{z} 782.5,1074.6,1102.6,1130.7$ and 1156.7 peaks. When we compared (A) IMS with (B) a hematoxylin and eosin-stained section, the peaks of Gb3s were more densely packed in cardiomyocytes with vacuolar degeneration, and the Gb3s existed together in some parts and separately in others. (C,D) In contrast, $\mathrm{Gb} 3$ was not detected in a control sample from a patient with secondary myocardial degenerative changes with aortic regurgitation. (E,F) Gb3s were also detected on IMS in the heart of a mouse with Fabry's disease even though there was no evidence of vacuolar changes in the myocardium on light microscopy. Bar, $200 \mu \mathrm{m}$. (Reprinted from ref. 67 from Official Journal of the Japanese Circulation Society.)

that the cancerous cells accumulated sphingomyelin. ${ }^{47)}$ We have also studied the localization of seminolipids in mouse testis during testicular maturation, and the organ-specific distribution of lysophosphotidylcholine and triacylglycerol in mouse embryos using IMS. ${ }^{45,59)}$ Recently, our group has developed a TLC-Blot-MALDI-TOF-IMS system which can separate and partially characterize acidic and neutral GSLs. Here, we describe gangliosides identified from a control patient and a patient with Alzheimer's disease using TLC-Blot-MALDI-TOF-MS imaging of the hippocampus gray matter (Fig. 1). In the Alzheimer's patient, the GM2 and GD3 ganglioside bands appeared to be clearer than those of the control. The relative increases in d18:1 sphingosine-containing gangliosides in the patient with Alzheimer's disease are also expressed in this image. ${ }^{60)}$

2.2. Imaging of Proteins and Peptides Immunohistochemistry has been commonly used for profiling protein distribution in tissue sections. In this approach, antibodies are needed to detect specific proteins. Other genomic and proteomic approaches cannot be applied to biopsies as the quantity of sample available is only very small..$^{14,61-63)}$ Our group has analyzed SCRAPPER (A protein we first reported that is localized in neuronal synapses. $)^{6}$ knockout mouse by utilizing a proteomic approach based on an IMS technique. ${ }^{64)}$ We have also demonstrated that the denaturation process and detergent-supplemented trypsin solution can improve the protein digestion efficiency for direct tissue analysis with IMS. ${ }^{65}$ ) We recently developed a formalin-fixed paraffin-embedded 


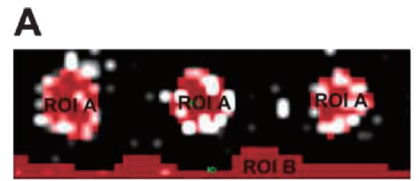

Signal intensity
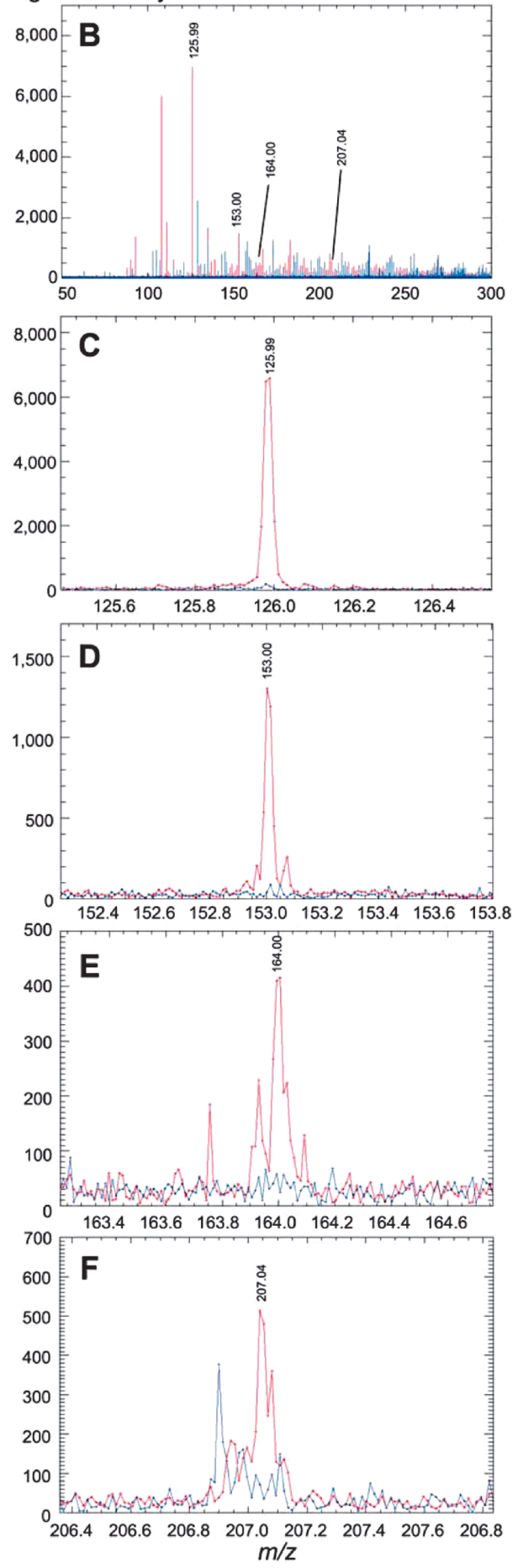

Fig. 4. Hair-Specific Mass Spectra of Putative Aging Markers

ROI-specific mass spectra in subject No. 1 are presented. Red peaks and blue peaks are derived from the hair section and background area, respectively. (A) ROI selection is illustrated: ROI A as hair section and ROI B as background area. (B) $\mathrm{m} / z 50$ to 300. (C) $\mathrm{m} / \mathrm{z}$ 125.99. (D) $\mathrm{m} / \mathrm{z}$ 153.00. (E) $\mathrm{m} / \mathrm{z}$ 164.00. (F) $\mathrm{m} / \mathrm{z} 207.04$. (Reprinted from ref. 68 with permission from The Public Library of Science.) tissue microarray to study gastric carcinoma tissue samples by IMS, and successfully identified histone (H4)-specific signals in poorly differentiated cancer tissue samples by utilizing tandem MS. ${ }^{63)}$ Proteomic-based IMS investigations have resulted in a better understanding of carcinogenesis, invasiveness, metastasis, and the prognosis process in gastric cancer patients.

\section{DEVELOPMENT AND APPLICATION OF HIGH- RESOLUTION ATMOSPHERIC PRESSURE-LASER MASS MICROSCOPE}

3.1. Development of a 'Mass Microscope' Recently, we have developed a 'mass microscope' consisting of a microscope coupled with high-resolution atmospheric pressure-laser desorption/ionization (AP-LDI) and a quadruple ion trap-time-of-flight (QIT-TOF)-analyzer ${ }^{66)}$ (Fig. 2). This instrument allows us to precisely observe a specific tissue section before IMS and analyze the biomolecules with a spatial resolution of $10 \mu \mathrm{m}$ on the tissue section. An UV laser tightly focused with a triplet lens was used to achieve high spatial resolution. An atmospheric pressure ion-source chamber enables us to analyze fresh samples with minimal loss of intrinsic water or volatile compounds.

3.2. Analysis of Disease Biomarkers in Fabry's Disease We have used IMS to achieve the accurate diagnosis of Fabry's disease, especially in questionable cases, and have shown that IMS has a higher specificity than electron microscopy or enzyme activity assays, which are based on light microscopy. We constructed images by determining the locations of these peaks within an endomyocardial (EMB) biopsy sample. ${ }^{67)}$ We observed that the distribution of globotriaosylceramides (Gb3s) was consistent with that of cardiomyocytes, especially in areas that were affected by vacuolar degeneration, and that the Gb3 types existed together in some parts and separately in others (Figs. 3A, B). In contrast, as shown in Figs. 3C and $\mathrm{D}, \mathrm{Gb} 3$ was not detected in the control EMB sample. When we analyzed the heart from a mouse with Fabry's disease, we also detected $\mathrm{Gb} 3 \mathrm{~s}$ in the cardiac tissue, even though there was no evidence of vacuolation in the cardiomyocytes on light microscopy (Figs. 3E, F). Gb3 was not detected in the control mouse heart. We could detect Gb3s not only in the heart from a Fabry's disease patient, but also in the heart from a mouse model of Fabry's disease without discernible degenerative changes on light microscopy. Although the significance of each type of $\mathrm{Gb3}$ distribution is unknown, it is possible that these distribution patterns could help to distinguish variations in the disease phenotype or evaluate the effectiveness of enzyme replacement therapy, which may also help to elucidate the basis for the disease. However, this issue requires further study. The current study presents novel findings suggesting that IMS is useful for diagnosing Fabry's disease with cardiac manifestations, especially in questionable cases. Because IMS can directly analyze the molecular weight of each existing component, IMS has a higher specificity than electron microscopy or enzyme activity assays when Fabry's disease is suspected based on light microscopy. Our results indicate that IMS is a new tool that can be used to accurately diagnose not only Fabry's disease, but also other unknown storage diseases.

3.3. Analysis of Biomolecules in Human Hair The mass microscope has a subcellular spatial resolution of $10 \mu \mathrm{m}$ for the detection of molecules from a tissue section. We have 

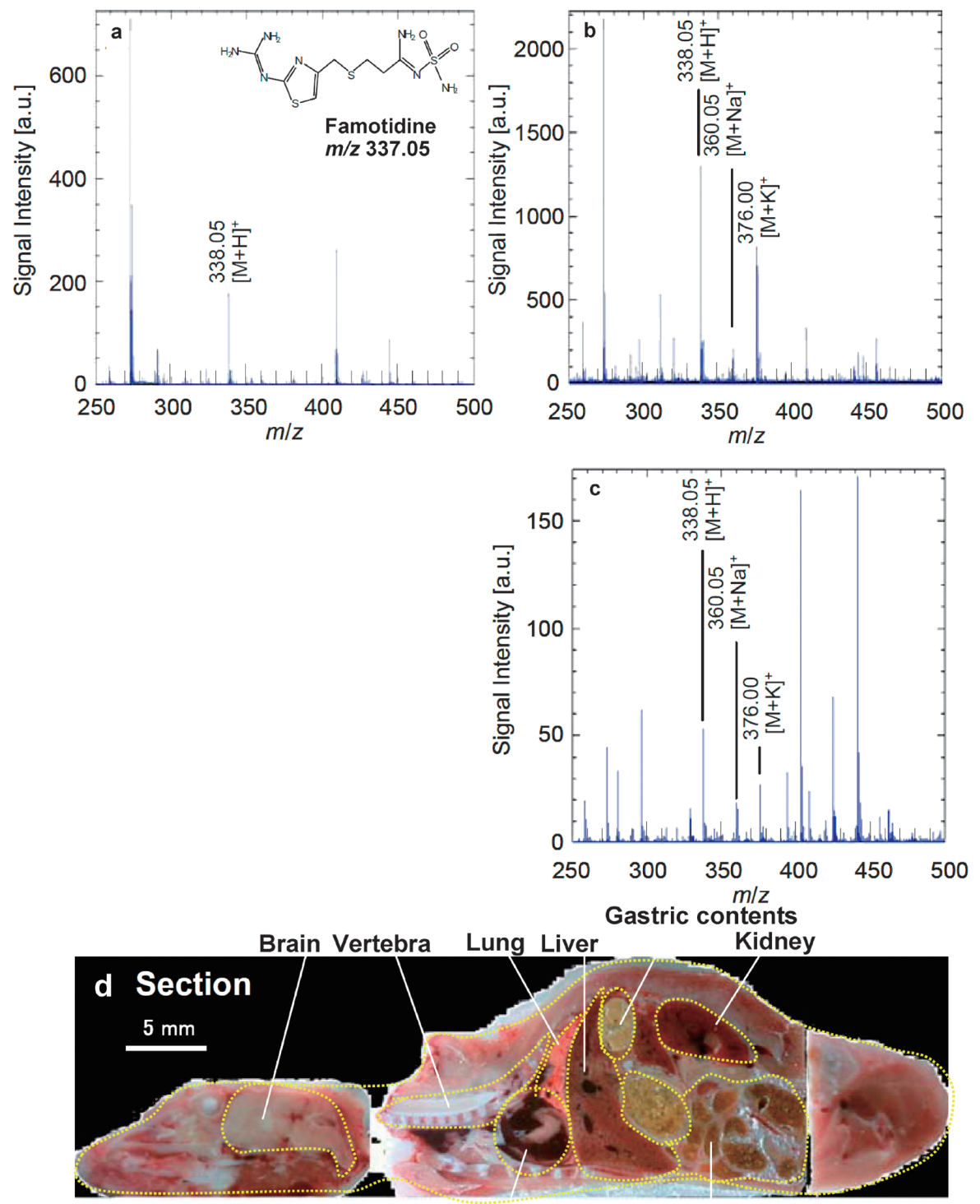

Heart

Intestinal contents

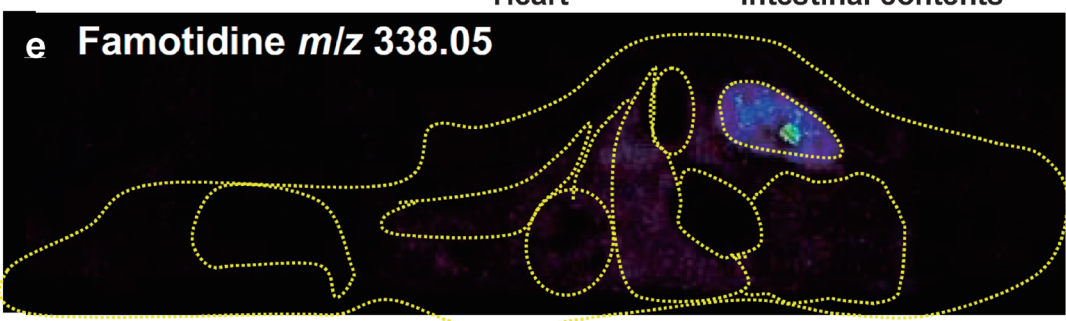

High

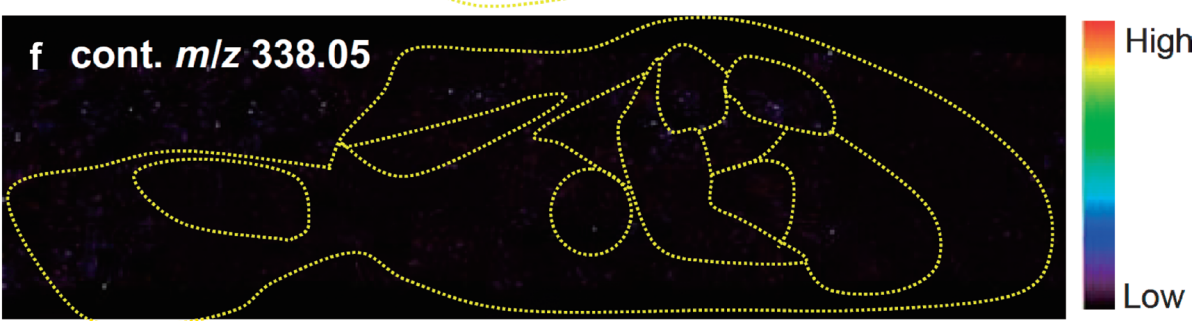

Fig. 5. Mass Spectrum of Famotidine and an MS Ion Image of a Whole-Body Section

(A) Structure and mass spectrum of famotidine. (B) Mass spectrum of famotidine detected in a tissue section. (C) Mass spectrum of famotidine detected in the kidney in a tissue section. (D) Optical image of a mouse tissue section. (E) MS ion image of famotidine $(\mathrm{m} / \mathrm{z} 338.05)$ on a mouse tissue section 3 min after injection. Famotidine is localized to a significant extent in the kidney. (F) MS ion image at $\mathrm{m} / \mathrm{z} 338.05$ on a control mouse tissue section. (Reprinted from ref. 69 with permission from Journal of the Mass Spectrometry Society of Japan.) 
applied this system to analyze human hair cross sections, and have detected biomolecules showing aging-related alterations. The optical images obtained at high resolution showed molecular distribution in the cortex and medulla region of hair. ${ }^{68)}$ Among the 31 molecules detected specifically in hair sections, dihydrouracil and 3,4-dihydroxymandelic acid (DHMA), which are metabolites of uracil and catecholamines, respectively, exhibited a higher signal intensity in the young group than in the old, and $O$-phosphoethanolamine displayed a higher intensity in the old group (Fig. 4). Among the 3, putative $O$-phosphoethanolamine showed a cortex-specific distribution, and exhibited changes in signal intensity with aging, whereas the molecules in medulla did not exhibit significant changes.

3.4. Analysis of Drug Distribution Imaging of drugs and metabolites by MALDI-IMS offers a unique opportunity to identify changes in the distribution of a desired compound in different regions of a tissue of interest, and this technique can help us to understand whether an exogenous compound administered orally affects endogenous metabolites. Antipsychotic, cancer, anti-anxiety, and hypnotic drugs have been studied in different tissue sections by IMS to determine the distribution of molecules. ${ }^{43)}$ In these assays, a multivariate approach with MALDI-IMS is useful to investigate the dynamics of metabolites. ${ }^{44)}$ Recently, we attempted to visualize the distribution of famotidine with a higher spatial resolution in whole body mouse sections using the mass microscope that we developed, and observed famotidine was mainly distributed in the kidney (Fig. 5). ${ }^{69)}$ Moreover, a higher spatial-resolution analysis revealed that the distribution of famotidine was in the renal pelvis of the kidney. The results suggest that famotidine is concentrated in the renal pelvis through the cortex and marrow in the kidney during the excretion process. It can therefore be concluded that the mass microscope permits deeper insight into therapeutic and toxicological processes associated with drug administration.

\section{FUTURE PERSPECTIVES}

Many great advances have been made in MALDI-IMS to resolve molecular species in various types of biological samples, but there is still room for improvement with respect to sample preparation, ionization, and instrumentation. The mass microscope could be a powerful tool for obtaining high resolution of biomolecules in tissue samples. The fundamental contributions of MALDI-IMS will provide a powerful tool for the early detection and characterization of cellular processes in both healthy and disease conditions, and help us to understand and treat disorders very effectively.

Acknowledgments This review was undertaken on behalf of The Pharmaceutical Society of Japan for Awarding the Promotion Prize to M.S. for the development and application of IMS techniques and mass microscope. We would like to acknowledge the collaboration of past and present colleagues in the Department of Cell Biology and Anatomy of Hamamatsu University School of Medicine, Shimadzu Corporation, and many other collaborators for their work that was reviewed in this paper and supported mainly by the Japanese Science and Technology Agency (JST) in the form of a Grant-in-Aid for SENTAN.

\section{REFERENCES}

1) Kevles B. Naked to the Bone: Medical Imaging in the Twentieth Century. Rutgers University Press, New Brunswick, New Jersey, 1997.

2) Weissleder R, Moore A, Mahmood U, Bhorade R, Benveniste H, Chiocca EA, Basilion JP. In vivo magnetic resonance imaging of transgene expression. Nat. Med., 6, 351-355 (2000).

3) Setou M, Radostin D, Atsuzawa K, Yao I, Fukuda Y, Usuda N, Nagayama K. Mammalian cell nano structures visualized by cryo Hilbert differential contrast transmission electron microscopy. Med. Mol. Morphol., 39, 176-180 (2006).

4) Phelps ME, Hoffman EJ, Mullani NA, Ter-Pogossian MM. Application of annihilation coincidence detection to transaxial reconstruction tomography. Journal of Nuclear Medicine, 16, 210-224 (1975).

5) Ikegami K, Heier RL, Taruishi M, Takagi H, Mukai M, Shimma S, Taira S, Hatanaka K, Morone N, Yao I, Campbell PK, Yuasa S, Janke C, Macgregor GR, Setou M. Loss of alpha-tubulin polyglutamylation in ROSA22 mice is associated with abnormal targeting of KIF1A and modulated synaptic function. Proc. Natl. Acad. Sci. U.S.A., 104, 3213-3218 (2007).

6) Yao I, Takagi H, Ageta H, Kahyo T, Sato S, Hatanaka K, Fukuda Y, Chiba T, Morone N, Yuasa S, Inokuchi K, Ohtsuka T, Macgregor GR, Tanaka K, Setou M. SCRAPPER-dependent ubiquitination of active zone protein RIM1 regulates synaptic vesicle release. Cell, 130, 943-957 (2007).

7) Hatanaka T, Hatanaka Y, Setou M. Regulation of amino acid transporter ATA2 by ubiquitin ligase Nedd4-2. J. Biol. Chem., 281, 35922-35930 (2006).

8) Ikegami K, Mukai M, Tsuchida J, Heier RL, Macgregor GR, Setou M. TTLL7 is a mammalian beta-tubulin polyglutamylase required for growth of MAP2-positive neurites. J. Biol. Chem., 281, $30707-$ 30716 (2006).

9) Hatanaka T, Hatanaka Y, Tsuchida J-i, Ganapathy V, Setou M. Amino acid transporter ATA2 is stored at the trans-Golgi network and released by insulin stimulus in adipocytes. J. Biol. Chem., 281, 39273-39284 (2006).

10) Konishi Y, Setou M. Tubulin tyrosination navigates the kinesin-1 motor domain to axons. Nat. Neurosci., 12, 559-567 (2009).

11) Yang HJ, Takagi H, Konishi Y, Ageta H, Ikegami K, Yao I, Sato S, Hatanaka K, Inokuchi K, Seog DH, Setou M. Transmembrane and ubiquitin-like domain-containing protein 1 (Tmubl/HOPS) facilitates surface expression of GluR2-containing AMPA receptors. PLoS ONE, 3, 1-13 (2008).

12) Fukuda $Y$, Kawano $Y$, Tanikawa $Y$, Oba M, Koyama M, Takagi $\mathrm{H}$, Matsumoto M, Nagayama K, Setou M. In vivo imaging of the dendritic arbors of layer $\mathrm{V}$ pyramidal cells in the cerebral cortex using a laser scanning microscope with a stick-type objective lens. Neurosci. Lett., 400, 53-57 (2006).

13) Asai S, Takamura K, Suzuki H, Setou M. Single-cell imaging of c-fos expression in rat primary hippocampal cells using a luminescence microscope. Neurosci. Lett., 434, 289-292 (2008).

14) Setou M, Seog D-H, Tanaka Y, Kanai Y, Takei Y, Kawagishi M, Hirokawa N. Glutamate-receptor-interacting protein GRIP1 directly steers kinesin to dendrites. Nature, 417, 83-87 (2002).

15) Luxembourg SL, Mize TH, McDonnell LA, Heeren RMA. High-spatial resolution mass spectrometric imaging of peptide and protein distributions on a surface. Anal. Chem., 76, 5339-5344 (2004).

16) Brotherton HO, Yost RA. Determination of drugs in blood serum by mass spectrometry/mass spectrometry. Anal. Chem., 55, 549-553 (1983).

17) Johnson JV, Yost RA, Faull KF. Tandem mass spectrometry for the trace determination of tryptolines in crude brain extracts. Anal. Chem., 56, 1655-1661 (1984).

18) Bernier UR, Kline DL, Barnard DR, Schreck CE, Yost RA. 
Analysis of human skin emanations by gas chromatography/mass spectrometry. 2. Identification of volatile compounds that are candidate attractants for the yellow fever mosquito (Aedes aegypti). Anal. Chem., 72, 747-756 (2000).

19) Garrett TJ, Yost RA. Analysis of intact tissue by intermediate-pressure MALDI on a linear ion trap mass spectrometer. Anal. Chem., 78, 2465-2469 (2006).

20) Rubakhin SS, Greenough WT, Sweedler JV. Spatial profiling with MALDI MS: distribution of neuropeptides within single neurons. Anal. Chem., 75, 5374-5380 (2003).

21) Rubakhin SS, Churchill JD, Greenough WT, Sweedler JV. Profiling signaling peptides in single mammalian cells using mass spectrometry. Anal. Chem., 78, 7267-7272 (2006).

22) Miao H, Rubakhin SS, Sweedler JV. Subcellular analysis of D-aspartate. Anal. Chem., 77, 7190-7194 (2005).

23) Hatcher NG, Richmond TA, Rubakhin SS, Sweedler JV. Monitoring activity-dependent peptide release from the CNS using single-bead solid-phase extraction and MALDI TOF MS detection. Anal. Chem., 77, 1580-1587 (2005).

24) Sugiura $Y$, Shimma S, Setou M. Two-step matrix application technique to improve ionization efficiency for matrix-assisted laser desorption/ionization in imaging mass spectrometry. Anal. Chem., 78, 8227-8235 (2006).

25) Shimma S, Furuta M, Ichimura K, Yoshida Y, Setou M. A novel approach to in situ proteome analysis using chemical inkjet printing technology and MALDI-QIT-TOF tandem mass spectrometer. Journal of the Mass Spectrometry Society of Japan, 54, 133-140 (2006).

26) Shimma S, Furuta M, Ichimura K, Yoshida Y, Setou M. Direct MS/MS analysis in mammalian tissue sections using MALDIQIT-TOF-MS and chemical inkjet technology. Surf. Interface Anal., 38, 12-13, 1712-1714 (2006).

27) Chaurand P, Schwartz SA, Reyzer ML, Caprioli RM. Imaging mass spectrometry: principles and potentials. Toxicol. Pathol., 33, 92-101 (2005).

28) Stoeckli M, Chaurand P, Hallahan DE, Caprioli RM. Imaging mass spectrometry: a new technology for the analysis of protein expression in mammalian tissues. Nat. Med., 7, 493-496 (2001).

29) Sugiura Y, Shimma S, Moriyama Y, Setou M. Direct analysis of cultured cells with matrix-assisted laser desorption/ionization on conductive transparent film. Journal of the Mass Spectrometry Society of Japan, 55, 25-31 (2007).

30) Chaurand P, Schriver KE, Caprioli RM. Instrument design and characterization for high resolution MALDI-MS imaging of tissue sections. J. Mass Spectrom., 42, 476-489 (2007).

31) Schwartz SA, Weil RJ, Johnson MD, Toms SA, Caprioli RM. Protein profiling in brain tumors using mass spectrometry: feasibility of a new technique for the analysis of protein expression. Clin. Cancer Res., 10, 981-987 (2004).

32) Pierson J, Norris JL, Aerni HR, Svenningsson P, Caprioli RM, Andrén PE. Molecular profiling of experimental Parkinson's disease: direct analysis of peptides and proteins on brain tissue sections by MALDI mass spectrometry. J. Proteome Res., 3, 289-295 (2004).

33) Jackson SN, Wang H-YJ, Woods AS. In situ structural characterization of phosphatidylcholines in brain tissue using MALDI-MS/MS. J. Am. Soc. Mass Spectrom., 16, 2052-2056 (2005).

34) Jackson SN, Wang H-YJ, Woods AS, Ugarov M, Egan T, Schultz JA. Direct tissue analysis of phospholipids in rat brain using MALDI-TOFMS and MALDI-ion mobility-TOFMS. J. Am. Soc. Mass Spectrom., 16, 133-138 (2005).

35) Touboul D, Piednoël H, Voisin V, De La Porte S, Brunelle A, Halgand F, Laprévote $\mathrm{O}$. Changes of phospholipid composition within the dystrophic muscle by matrix-assisted laser desorption/ionization mass spectrometry and mass spectrometry imaging. Eur. J. Mass Spectrom. (Chichester, Eng.), 10, 657-664 (2004).

36) Khatib-Shahidi S, Andersson M, Herman JL, Gillespie TA, Caprioli RM. Direct molecular analysis of whole-body animal tissue sections by imaging MALDI mass spectrometry. Anal. Chem., 78, 6448-6456 (2006).

37) Takáts Z, Wiseman JM, Gologan B, Cooks RG. Mass spectrometry sampling under ambient conditions with desorption electrospray ionization. Science, 306, 471-473 (2004).

38) Benninghoven A. Surface investigation of solids by the statical method of secondary ion mass spectroscopy (SIMS). Surf. Sci., 35, 427-457 (1973)

39) Tanaka K, Waki H, Ido Y, Akita S, Yoshida Y, Yoshida T, Matsuo T. Protein and polymer analyses up to $m / z 100000$ by laser ionization time-of-flight mass spectrometry. Rapid Commun. Mass Spectrom., 2, 151-153 (1988).

40) Rohner TC, Staab D, Stoeckli M. MALDI mass spectrometric imaging of biological tissue sections. Mech. Ageing Dev., 126, 177-185 (2005).

41) Shimma S, Sugiura $Y$, Hayasaka $T$, Zaima N, Matsumoto $M$, Setou M. Mass imaging and identification of biomolecules with MALDI-QIT-TOF-based system. Anal. Chem., 80, 878-885 (2008).

42) Sugiura Y, Konishi Y, Zaima N, Kajihara S, Nakanishi H, Taguchi $\mathrm{R}$, Setou M. Visualization of the cell-selective distribution of PUFA-containing phosphatidylcholines in mouse brain by imaging mass spectrometry. J. Lipid Res., 50, 1776-1788 (2009).

43) Sugiura Y, Shimma S, Konishi Y, Yamada MK, Setou M. Imaging mass spectrometry technology and application on ganglioside study; visualization of age-dependent accumulation of C20-ganglioside molecular species in the mouse hippocampus. PLoS ONE, 3, 1-9 (2008).

44) Zaima N, Matsuyama Y, Setou M. Principal component analysis of direct matrix-assisted laser desorption/ionization mass spectrometric data related to metabolites of fatty liver. J. Oleo Sci., $\mathbf{5 8}$, 267-273 (2009).

45) Goto-Inoue N, Hayasaka T, Zaima N, Setou M. The specific localization of seminolipid molecular species on mouse testis during testicular maturation revealed by imaging mass spectrometry. Glycobiology, 19, 950-957 (2009).

46) Hayasaka T, Goto-Inoue N, Sugiura $Y$, Zaima N, Nakanishi H, Ohishi K, Nakanishi S, Naito T, Taguchi R, Setou M. Matrix-assisted laser desorption/ionization quadrupole ion trap time-of-flight (MALDI-QIT-TOF)-based imaging mass spectrometry reveals a layered distribution of phospholipid molecular species in the mouse retina. Rapid Commun. Mass Spectrom., 22, 3415-3426 (2008).

47) Shimma S, Sugiura Y, Hayasaka T, Hoshikawa Y, Noda T, Setou M. MALDI-based imaging mass spectrometry revealed abnormal distribution of phospholipids in colon cancer liver metastasis. J. Chromatogr. B Analyt. Technol. Biomed. Life Sci., 855, 98-103 (2007).

48) Hosokawa N, Sugiura Y, Setou M. Spectrum Normalization Method Using an External Standard in Mass Spectrometric Imaging. Journal of the Mass Spectrometry Society of Japan, 56, 77-81 (2008).

49) Goto-Inoue N, Hayasaka T, Sugiura Y, Taki T, Li YT, Matsumoto M, Setou M. High-sensitivity analysis of glycosphingolipids by matrix-assisted laser desorption/ionization quadrupole ion trap time-of-flight imaging mass spectrometry on transfer membranes. $J$. Chromatogr. B, 870, 74-83 (2008).

50) Sugiura Y, Shimma S, Setou M. Thin sectioning improves the peak intensity and signal-to-noise ratio in direct tissue mass spectrometry. Journal of the Mass Spectrometry Society of Japan, 54, 45-48 (2006).

51) Taira S, Sugiura Y, Moritake S, Shimma S, Ichiyanagi Y, Setou M. Nanoparticle-assisted laser desorption/ionization based mass imaging with cellular resolution. Anal. Chem., 80, 4761-4766 (2008).

52) Moritake S, Taira S, Sugiura Y, Setou M, Ichiyanagi Y. Magnetic nanoparticle-based mass spectrometry for the detection of biomolecules in cultured cells. J. Nanosci. Nanotechnol., 9, 169-176 (2009).

53) Ageta H, Asai S, Sugiura Y, Goto-Inoue N, Zaima N, Setou M. Layer-specific sulfatide localization in rat hippocampus middle molecular layer is revealed by nanoparticle-assisted laser desorption/ 
ionization imaging mass spectrometry. Med. Mol. Morphol., 42, 16-23 (2009).

54) Nakagawa $T$, Setou M, Seog D, Ogasawara K, Dohmae N, Takio K, Hirokawa N. A novel motor, KIF13A, transports mannose-6-phosphate receptor to plasma membrane through direct interaction with AP-1 complex. Cell, 103, 569-581 (2000).

55) Setou M, Nakagawa T, Seog D-H, Hirokawa N. Kinesin superfamily motor protein KIF17 and mLin-10 in NMDA receptor-containing vesicle transport. Science, 288, 1796-1802 (2000).

56) Müthing J. High-resolution thin-layer chromatography of gangliosides. J. Chromatogr. A, 720, 3-25 (1996).

57) van Echten-Deckert G. Sphingolipid extraction and analysis by thinlayer chromatography. Methods Enzymol., 312, 64-79 (2000).

58) Yu RK, Ariga T. Ganglioside analysis by high-performance thinlayer chromatography. Methods Enzymol., 312, 115-134 (2000).

59) Hayasaka T, Goto-Inoue N, Zaima N, Kimura Y, Setou M. Organ-specific distributions of lysophosphatidylcholine and triacylglycerol in mouse embryo. Lipids, 44, 837-848 (2009).

60) Valdes-Gonzalez T, Goto-Inoue $\mathrm{N}$, Hirano W, Ishiyama $\mathrm{H}$, Hayasaka T, Setou M, Taki T. New approach for glyco- and lipidomics-molecular scanning of human brain gangliosides by TLC-Blot and MALDI-QIT-TOF MS. J. Neurochem., 116, 678-683 (2011).

61) Ikegami K, Horigome D, Mukai M, Livnat I, MacGregor GR, Setou M. TTLL10 is a protein polyglycylase that can modify nucleosome assembly protein 1. FEBS Lett., 582, 1129-1134 (2008).

62) Hatanaka K, Ikegami K, Takagi H, Setou M. Hypo-osmotic shock induces nuclear export and proteasome-dependent decrease of UBL5. Biochem. Biophys. Res. Commun., 350, 610-615 (2006).

63) Morita Y, Ikegami K, Goto-Inoue N, Hayasaka T, Zaima N, Tanaka
H, Uehara T, Setoguchi T, Sakaguchi T, Igarashi H, Sugimura H, Setou M, Konno H. Imaging mass spectrometry of gastric carcinoma in formalin-fixed paraffin-embedded tissue microarray. Cancer Sci., 101, 267-273 (2010).

64) Yao I, Sugiura Y, Matsumoto M, Setou M. In situ proteomics with imaging mass spectrometry and principal component analysis in the Scrapper-knockout mouse brain. Proteomics, 8, 3692-3701 (2008).

65) Setou M, Hayasaka T, Shimma S, Sugiura Y, Matsumoto M. Protein denaturation improves enzymatic digestion efficiency for direct tissue analysis using mass spectrometry. Appl. Surf. Sci., 255, 1555-1559 (2008).

66) Harada T, Yuba-Kubo A, Sugiura Y, Zaima N, Hayasaka T, Goto-Inoue N, Wakui M, Suematsu M, Takeshita K, Ogawa K, Yoshida Y, Setou M. Visualization of volatile substances in different organelles with an atmospheric-pressure mass microscope. Anal. Chem., 81, 9153-9157 (2009).

67) Onoue K, Zaima N, Sugiura Y, Isojima T, Okayama S, Horii M, Akai Y, Uemura S, Takemura G, Sakuraba H, Sakaguchi Y, Setou M, Saito Y. Using imaging mass spectrometry to accurately diagnose Fabry's disease. Circ. J., 75, 221-223 (2011).

68) Waki ML, Onoue K, Takahashi T, Goto K, Saito Y, Inami K, Makita I, Angata Y, Suzuki T, Yamashita M, Sato N, Nakamura S, Yuki D, Sugiura Y, Zaima N, Goto-Inoue N, Hayasaka T, Shimomura Y, Setou M. Investigation by imaging mass spectrometry of biomarker candidates for aging in the hair cortex. PLoS ONE, 6, 1-9 (2011).

69) Saito Y, Hayasaka T, Onoue K, Takizawa Y, Kajihara S, Ogawa K, Setou M. Pharmacokinetic analysis using a high spatial-resolution mass microscope. Journal of the Mass Spectrometry Society of Japan, 59, 79-84 (2011). 